\title{
Tools for development of interactive web-based maps: application in healthcare
}

$\begin{array}{cc}\text { Matěj Karolyi } & \text { Jan Krejčí } \\ \text { Faculty of } & \text { Department of } \\ \text { Informatics, } & \text { Telecommunication } \\ \text { Masaryk University } & \text { s, Brno University of } \\ \text { Botanická 68a } & \text { Technology } \\ 602 \text { 00, Brno, } & \text { Technická 10 } \\ \text { Czech Republic } & 616 \text { 00, Brno, } \\ \text { karolyi@iba.muni.cz } & \text { Czech Republic } \\ & \text { krejci@iba.muni.cz }\end{array}$

\author{
Jakub Ščavnický \\ Institute of Health \\ Information and \\ Statistics of the \\ Czech Republic \\ and Institute of \\ Biostatistics and \\ Analyses, Faculty of \\ Medicine, Masaryk \\ University - joint \\ workplace \\ Palackého nám. 4 \\ 128 01, Praha 2, \\ Czech Republic \\ scavnicky \\ @iba.muni.cz
}

\author{
Roman Vyškovský \\ Institute of \\ Biostatistics and \\ Martin Komenda \\ Institute of Health \\ Analyses, Faculty of Statistics of the \\ Medicine, Masaryk \\ University \\ Kamenice 3 , \\ 625 00, Brno, \\ Czech Republic \\ vyskovsky \\ @iba.muni.cz \\ Czech Republic \\ and Institute of \\ Biostatistics and \\ Analyses, Faculty of \\ Medicine, Masaryk \\ University - joint \\ workplace \\ Palackého nám. 4 \\ 128 01, Praha 2, \\ Czech Republic \\ komenda \\ @iba.muni.cz
}

\begin{abstract}
Interactive visualisations on the Internet have become commonplace in recent years. Based on such publicly available visualisations, users can obtain information from various domains quickly and easily. A locationspecific method of data presentation can be much more effective using map visualisation than using traditional methods of data visualisation, such as tables or graphs. This paper presents one of the possible ways of creating map visualisations in a modern web environment. In particular, we introduce the technologies used in our case together with their detailed configuration. This description can then serve as a guide for the customisation of the server environment and application settings so that it is easy to create the described type of visualisation outputs. Together with this manual, specific cases are presented on the example of an application which was developed to display the location of medical equipment in the Czech Republic based on data collected from healthcare providers.
\end{abstract}

\section{Keywords}

medical equipment, data analysis, map visualisation, healthcare, Czech Republic.

\section{INTRODUCTION}

Data visualisation is a huge interdisciplinary domain that has reached mainstream consciousness: an ever increasing number of not only professionals, but also academic, government and business organisations have become interested and involved in this matter [Kirk16]. Proper data visualisation requires the understanding of input data, which can often be rather complex, combined with an analytical point of view of data processing as well as the interpretation by end users. Each new opportunity for data visualisation represents a new and unique presentation of a certain data set. Development and implementation of any innovative and interactive web-based project of data visualisation is quite a challenging issue in terms of smooth and effective delivery of presented information to selected target groups of users
[Murr17]. The main goal should always be to help users explore available data sets based on different views and allow them to choose their own ways of obtaining customised data subsets. Geographic maps are one of the most commonly used approaches for data visualisation. It has been used as a metaphor for visualisation, which produce a more readable form for those people who are familiar with reading maps [BYPA15].

With the proliferation of information graphics and online tools that create interactive data visualisations, combined with research that shows the effectiveness of including visuals in medical and healthcare fields, there is an increased urgency to determine effective practices for their creation and use [MeWa17]. In this particular domain, many modern and interesting projects aspire to present their data sets using web- 
based map visualisations to make high-quality information available to anyone interested. With the growing trend of health data production among all involved stakeholders, data visualisation applications have become very popular in the last decade. Several recent examples are briefly introduced below. The Institute for Health Metrics and Evaluation ${ }^{1}$ aims to improve the health of the world's populations by providing the best information on population health. UNICEF and the World Health Organisation ${ }^{2}$ have together developed a web portal containing all available data and the latest child mortality estimates for each country. The Health Intelligence project ${ }^{3}$ highlights applications on how data can be used, transformed to meaningful information and subsequently communicated online. It represents an integrated set of data, methods and processes, tools and individuals working together in order to turn health data in insights and actionable information, converting information into evidence and knowledge, and ultimately communicating findings, results, and key messages to all those who need them.

\section{Purpose of the Map of Medical Equipment}

The joint workplace of the Institute of Health Information and Statistics (IHIS) of the Czech Republic and the Institute of Biostatistics and Analyses (IBA), Faculty of Medicine, Masaryk University has been producing a large amount of valuable analyses, reports and publications intended for the general public, representatives of regional authorities as well as healthcare providers. Selected results are also presented online in the form of interactive data browsers (dynamic presentation of data) and slideshows presentation tools (static presentation of data).

The Map of Medical Equipment (MME), which is available at https://ztnemocnice.uzis.cz, is a pilot representative of an interactive web-based application aimed at displaying the availability of different categories of medical equipment in individual healthcare providers in the Czech Republic. The map was developed under the guarantee of the joint workplace of IHIS and IBA. The use of all the developed map visualisation has the significant advantage that most people understand geographic maps easily thanks to their early exposure to maps in schools. In nowadays in no such as application in Czech governmental sphere which shows locations of bought medical equipment by healthcare providers. Therefore, this tool is useful for checking this kind of

\footnotetext{
${ }^{1} \mathrm{http} / / / \mathrm{www} \cdot$ healthdata.org

${ }^{2} \mathrm{http} / / / \mathrm{www}$. childmortality.org

${ }^{3} \mathrm{http}: / / \mathrm{www}$. publichealthintelligence.org
}

information by governmental workers, healthcare facilities' stakeholders and citizens.

\section{METHODS}

The IHIS is responsible for the development of the platform as well as for the preparation of underlying data. As part of the development, the application is continuously automatically deployed on development servers, where their internal review can be carried out by a wider group of workers and guarantors. After approving individual bundles of changes, it is then deployed to IHIS production servers. The deployment process is partially automated using the Jenkins automation server [Jenk00].

\section{Deployment environment}

The deployment environment consists of four mutually dependent instances: (i) a development webserver with a continuous integration system, (ii) a production webserver, (iii) an application server with a distributed version control system and (iv) an application server with map sources. All of the above-mentioned instances are scalable virtual machines located on the same physical machine. An Ubuntu Server 16.04 with Long Term Support (LTS) with the application packages described in Section 3.1 provides the environment for running these servers.

\section{Data layer}

The data upon which the application is built are stored in a PostgreSQL 9.5 database system [Momj01, Post00]. The database was created in the Entity first way that can be performed with services provided by the Doctrine2 ORM framework [Dung13]. The database and public schema were created using the Symfony commands doctrine:database:create and doctrine:schema:create while the meta information about the database was taken from the symfony parameters.yml config file. After the entities were created, another command (doctrine:schema:update) was used to create database tables and sequences necessary to prepare the database for data import. This time, meta information was taken from the attribute annotation in the entity.

All steps necessary to make the data cleaned and prepared were performed in $\mathrm{R}$ language ${ }^{4}$, version 3.4.3. The tables were saved as csv files in UTF-8 encoding and the import itself was carried out using the pgAdmin III import tool. This tool also makes it possible to reimport the whole data set or import new data rows easily without the need for writing insert commands in cases when new data are delivered to the web development department.

\footnotetext{
${ }^{4}$ https://www.r-project.org/
} 


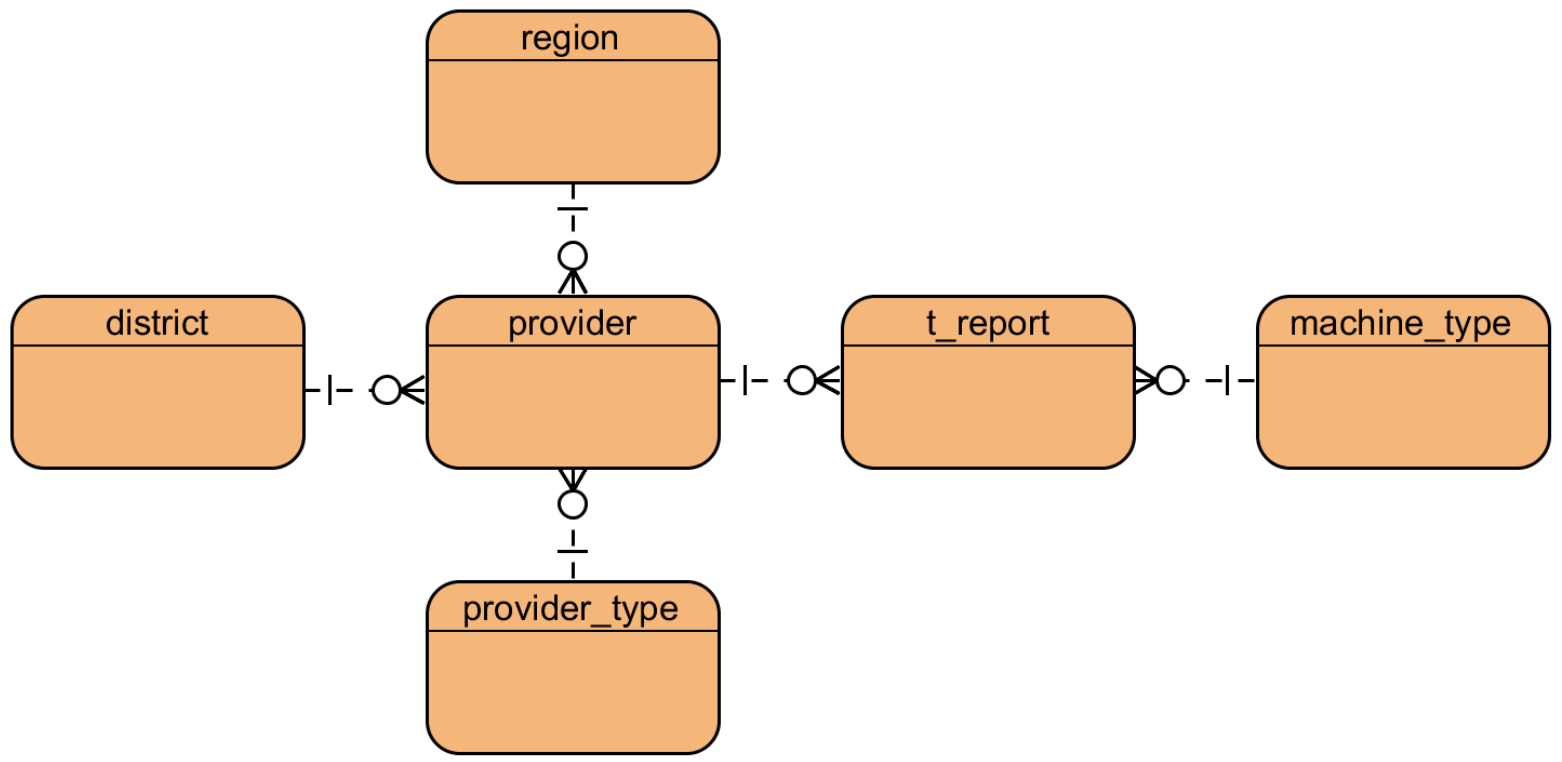

Figure 1: Conceptual model of database entities

The MME application is based on a simple database schema that relies mainly on two tables (conceptual model in Figure 1). The description of all healthcare facilities (hospitals, physicians, dentists etc.) providing any medical equipment is stored in the "provider" table. The reports containing the number and type of medical equipment provided by medical facilities are stored in the "t_report" table.

The schema is complemented by listings carrying the information of machine type, provider type, region and district.

\section{Data sources}

Data were obtained from two different sources: the National Register of Healthcare Providers ${ }^{5}$ and the Annual Report on Medical Equipment of a Healthcare Facility [Výka00]. The former contains a list of medical facilities; besides general information (such as the address and type of facility), GPS coordinates are also available, and these can be used to display the provider on a map. The latter source includes reports on equipment that must compulsorily be completed each year by all healthcare providers.

\section{Data preparation for visualisation with Leaflet}

Leaflet is an open-source library written in Javascript. It is used for the development of interactive maps within responsive web applications and portals. It works efficiently across all major desktop and mobile

\footnotetext{
${ }^{5}$ http://nrpzs.uzis.cz/
}

platforms. The core of Leaflet can be extended with various plugins (such as routing features, heatmaps, geocoding etc.) and weighs just about $38 \mathrm{kB}$ of Javascript code which is free to extend thanks to the open licensing [Leaf00].

Initialisation of a Leaflet map requires tile layer specification. There are many options for Leaflet map providers (see the official site at https://leafletjs.com/). We have used the OpenStreetMap tile layer in MME. After tiles are defined, initial map zoom, view and graphical points can be added. Each point requires GPS coordinates to be drawn. Furthermore, points may carry custom information in terms of their icon, colour or tooltip. The Leaflet map then becomes an interactive map that allows users to zoom in and out, move around a specific tile layer, click on specific points and display the included information.

\section{Types of views}

MME provides several views of the data. Users can get a comprehensive picture of the latest reported situation on medical equipment either across the Czech Republic or in individual regions or cities. Data selection can be refined by choosing a specific type of equipment or a specific region. The primary visualisation element is a map layer with an extra layer of points: each point symbolises a particular provider. If more than one healthcare providers are located at the same address (and therefore in the same coordinates), the point is shared. Details of individual healthcare providers are also available, combined with all necessary information (identification, name of institution, address, list of medical equipment). 
Last but not least, the search of the nearest providers with a certain type of technique is available based on the address entered and with optional navigation support. Some of views are described in the Results chapter.

\section{Geocoding with Nominatim}

Nominatim is a search engine for OpenStreetMap (OSM) data sources and can be generally described as a reverse geocoder for OSM data: it searches OSM data by name and address and generates synthetic addresses of OSM points. The tool is maintained under the General Public Licence (GPL) v2 licence and can be used as an own hosted installation (our use-case described as follows) or free service hosted ${ }^{6}$.

\subsubsection{Nominatim installation}

Nominatim is supported by Linux only, as a package for Ubuntu or Centos distributions or as a docker container [What00]. In case of own installation, it is important to follow the package requirements. Nominatim is dependent on the following general packages: (i) Python (version 3.0 or higher), (ii) PostgreSQL (version 9.1 or higher), (iii) PHP (version 5.4 or higher) and (iv) Apache or Nginx webserver. In addition, Nominatim requires some extra packages for its full operation: (i) GIS spatial DB backend for PostgreSQL - PostGIS (version 2.0 or higher) for storing structured OSM data and (ii) Osmium library for Python - PyOsmium, which maintain OSM data source up-to-date.

Hardware requirements for Nominatim depends on both the size and type of imported map sources. Most frequently, there are two types and sources of the maps: (i) original maps sources in the XML format are available on the OSM website ${ }^{7}$ or (ii) data extracts in OSM.PBF format ${ }^{8}$ are used. For our purpose, we chose data extracts for a number of reasons: (i) the package contains raw OSM data, (ii) the package is fully suitable for Nominatim, (iii) our data are $100 \%$ pure and unfiltered, (iv) the package contains all OSM metadata, (v) the packages are updated several times a day, (vi) our data are GDPR compliant, (vii) additional packages for Wikipedia rankings and Points of Interests are available and (viii) the package can be downloaded free of charge.

Maps can be imported for the entire Earth, for a selected continent or for a set of countries. Package sizes for example in our use-case are typically as follows: (i) 60GB for the entire Earth, (ii) 19GB for Europe or (iii) about $700 \mathrm{MB}$ for data source. General

\footnotetext{
${ }^{6} \mathrm{https} / / /$ nominatim.openstreetmap.org/

${ }^{7}$ https://planet.openstreetmap.org/

${ }^{8}$ https://download.geofabrik.de/
}

requirements (the interval mentioned below is defined from an import for one small country, such as the Czech Republic, an import for the entire Earth) are: (i) CPU from 2 to 6 cores with HyperThreading, (ii) RAM from $4 \mathrm{~GB}$ to $32 \mathrm{~GB}$ and (iii) HDD from $30 \mathrm{~GB}$ to $1 \mathrm{~TB}$ disk space. Data sources in the OSM format are compressed and after their import into the database, it will take more space and consume lot of computational time for the process of import. For example, data sources for the Czech Republic take up $700 \mathrm{MB}$ as source in a OSM file and $12 \mathrm{~GB}$ as raw data PostgreSQL database; their import takes 6 hours on SSD and 11 on mechanical HDD for an allocated four core virtual server with $8 \mathrm{~GB}$ RAM.

\section{Address resolving with Nominatim's API}

Address resolving can be carried out in two ways: (i) via a graphical user interface (GUI), provided by a Nominatim page running on the web server, see Figure 2 and Figure 3, or (ii) via an application

programming interface (API) using the standard HTTP methods.

The API is a tool used to search through OpenStreetMap data either by name and address (the user begins with the address and an appropriate geographic coordinate is returned) or by reverse geocoding (the user begins with a geographic coordinate and the nearest known address is returned).

The example query for resolving the address "Postovska3, Brno" geographic coordinate with request for address details; the XML output can be as follows:

\section{https://nominatim.openstreetmap.org/search? $q=3+p$ ostovska + brno\&format $=x m l \&$ polygon $=1 \&$ addressde tails $=1$}

For this query, the response shown in Figure 4 is returned.

Nominatim API supports national abbreviations for common short-term names for street and square terms and supports national and regional languages sets, queried as UTF-8 search strings.

\section{Results}

In this section, we describe the web-based application providing a complex overview and an advanced searching feature using interactive web-based maps. The first part is focused on the background of the whole application and should summarise all tools needed for the creation of such an application. The second part describes a specific part of MME from the user's point of view. 


\section{Technical description of the toolkit}

This paper summarises libraries, frameworks and operational system environment settings which are needed for the creation of interactive web-based map visualisations like these in MME.

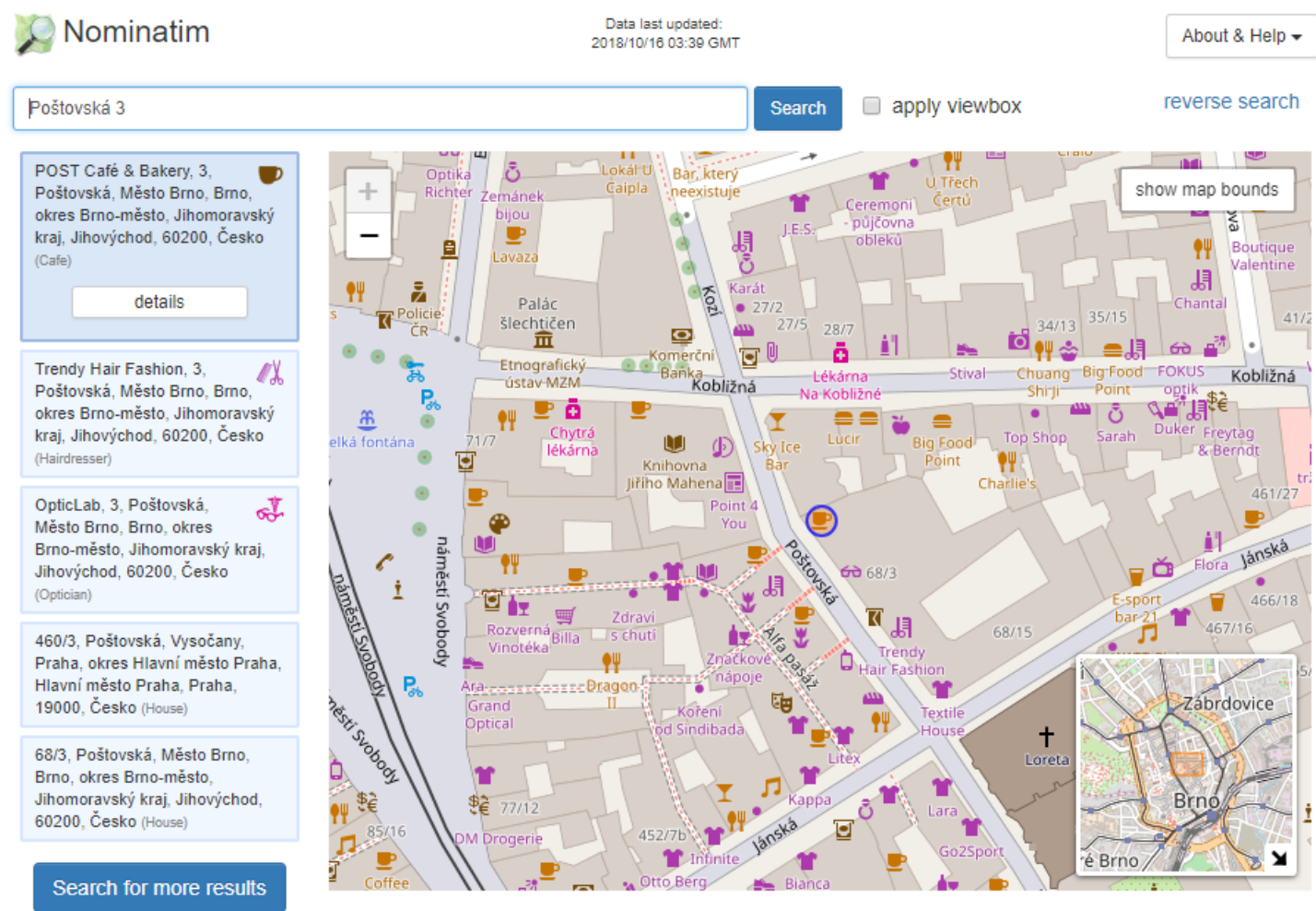

Figure 2: Nominatim query via GUI (search engine)

POST Café \& Bakery linkto this page $_{\text {en }}$

\begin{tabular}{ll}
\hline Name & POST Café \& Bakery (name) \\
\hline Type & amenity.cafe \\
\hline Last Updated & Sat, 18 Aug 18 22:25:19+0000 \\
\hline Admin Level & 15 \\
\hline Rank & Other: 30 \\
\hline Coverage & Point \\
\hline Centre Point & $49.1949894,16.6101582$ \\
\hline OSM & node 4823302943 \\
\hline Computed Postcode & 60200 \\
\hline Address Tags & Brno (city) \\
& 3(housenumber) \\
& 60200 (postcode) \\
& Poštovska (street) \\
\hline Extra Tags & Mo-Fr 07:00-18:00; Sa 08:00-12:00 (opening_hours) \\
& + +420 731 150 658 (phone) \\
& no (smoking) \\
& www.postbakery.cz (website)
\end{tabular}

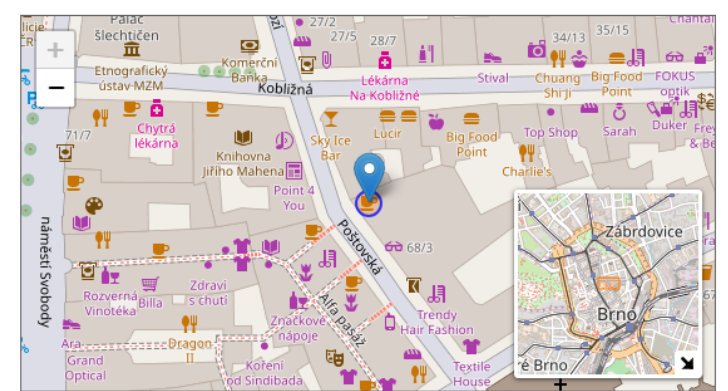

Adtress

\begin{tabular}{|lll|}
\hline Local name & Type & OSM \\
\hline POST Café \& Bakery & amenity:cafe & \\
\hline 3 & place:house_number & \\
\hline Poštovská & highway:pedestrian & way 16379444 \\
\hline Město Brno & boundary:administrative & relation 434760 \\
\hline Brno & place:city & relation 438171 \\
\hline okres Brno-město & boundary:administrative & relation 442273 \\
\hline Jihomoravský kraj & boundary:administrative & relation 442311 \\
\hline Jihovýchod & boundary:administrative & relation 435510 \\
\hline 60200 & place:postcode & \\
\hline Ċesko & place:country & relation 51684 \\
\hline
\end{tabular}

\begin{tabular}{llll} 
Address rank & Admin level & Distance & \\
29 & & 0 & details > \\
28 & & 0 & details $>$ \\
26 & & 0 & details > \\
20 & 10 & 0 & details > \\
16 & 8 & 0 & details > \\
14 & 7 & 0 & details > \\
12 & 6 & 0 & details $>$ \\
\hline 8 & 4 & 0 & details > \\
\hline 5 & 2 & 0 & \\
\hline 4 & & $\sim 1 \mathrm{~m}$ & details $>$ \\
\hline
\end{tabular}

Figure 3: Nominatim query via GUI interface (location detail) 


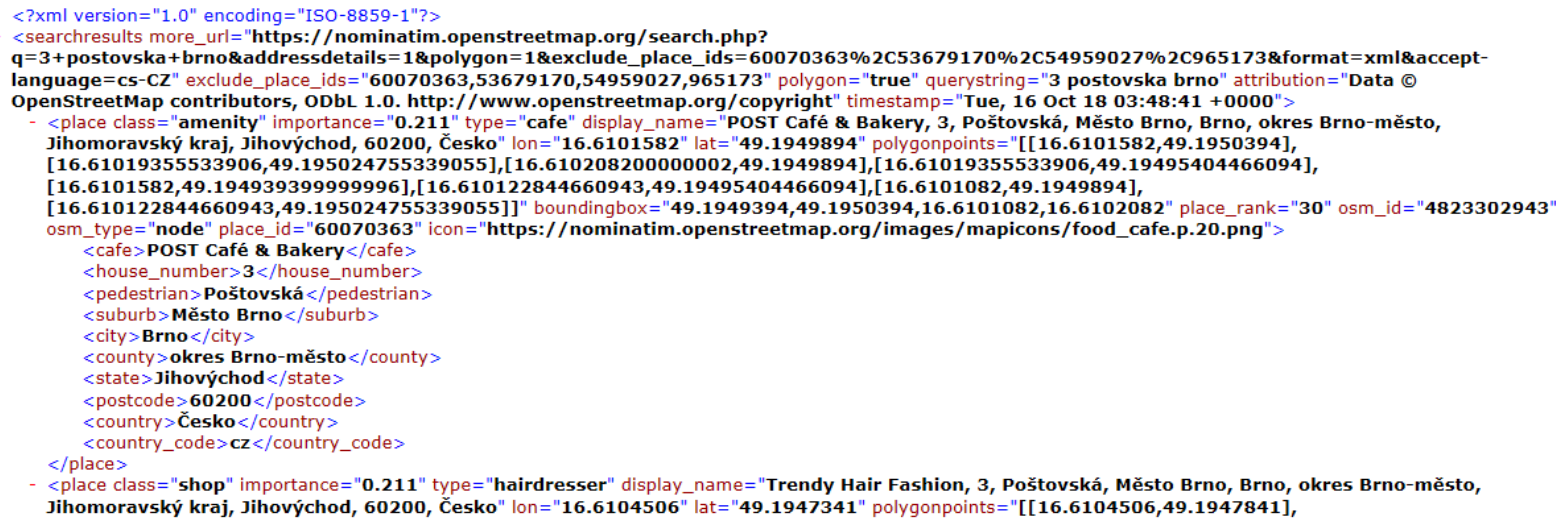

Figure 4: Nominatim query via an API interface (returned XML data for an example query)

Of course, that this is not the only approach possible and there could certainly be different equivalents; this is just an example shown on our specific case. The following list shows individual parts of the toolkit, divided into several categories:

- Operation system environment: Ubuntu 16.04, PHP 7.0, Python 3.0

- Persistent layer: PostgreSQL 9.5, Doctrine DBAL 2.8

- Application's backend: Symfony 3.4 framework for PHP. Doctrine ORM 2.5, Twig template engine 2.0

- Frontend and user interface: Leaflet 1.3, Select2 4.0, jQuery 2.2.4, d3.js 3.5

\section{Use case: Finding the nearest healthcare provider}

Based on this view of healthcare providers and their reported medical equipment, the user is able to find the closest providers with specific medical equipment quickly and easily. The typical user workflow is as follows:

- The user chooses which category of medical equipment or type of healthcare provider is interesting for him/her.

- The user then types the address he/she wants to find.

- The portal returns the list of suggested addresses that match the given expression.

- The user chooses one of the suggested addresses.

- The position of the chosen address is plotted on the map and a circle of ten-kilometre radius is highlighted from this address. All providers within a radius that meet the conditions selected in point 1 are displayed on the map and listed in a table below the map (see Figure 5).

- It is possible to increase or decrease the size of the above-mentioned radius by typing a specific value above the map.
- The user can then view the details of one of the listed providers or start navigating from the selected address to a healthcare provider.

\section{Discussion and future work}

The MME interactive portal provides a clear and comprehensive information about 15,104 pieces of medical equipment divided into 76 categories from a total of 209 healthcare providers, which are located in 14 regions in terms of global geographical overview and accessibility. The published data refer to all providers of inpatient care who have completed the obligatory Annual Report on Medical Equipment. The currently presented information (January 2019) on medical equipment is valid as of December 31, 2017. The user can choose among four ways of getting a detailed map of medical equipment of his/her interest: (i) searching by healthcare provider, using either provider name, VAT identification number or provider type, (ii) searching by medical equipment category, (iii) searching by region and district, (iv) accessibility searching by location using address, where all closest providers having selected medical equipment can easily be found in a particular distance radius. The results on a given query are always presented by geographic data in the form of a zoomable map as well as in the form of a data table with orderable columns.

We have created a non-trivial portal consisting of several map visualisations and detailed medical equipment listings. Collected data can be displayed from several different points of view, and individual views are connected with intelligible navigation. We have achieved this result by linking the technologies and tools described in this paper, which were combined together with an appropriate set-up of individual components. 


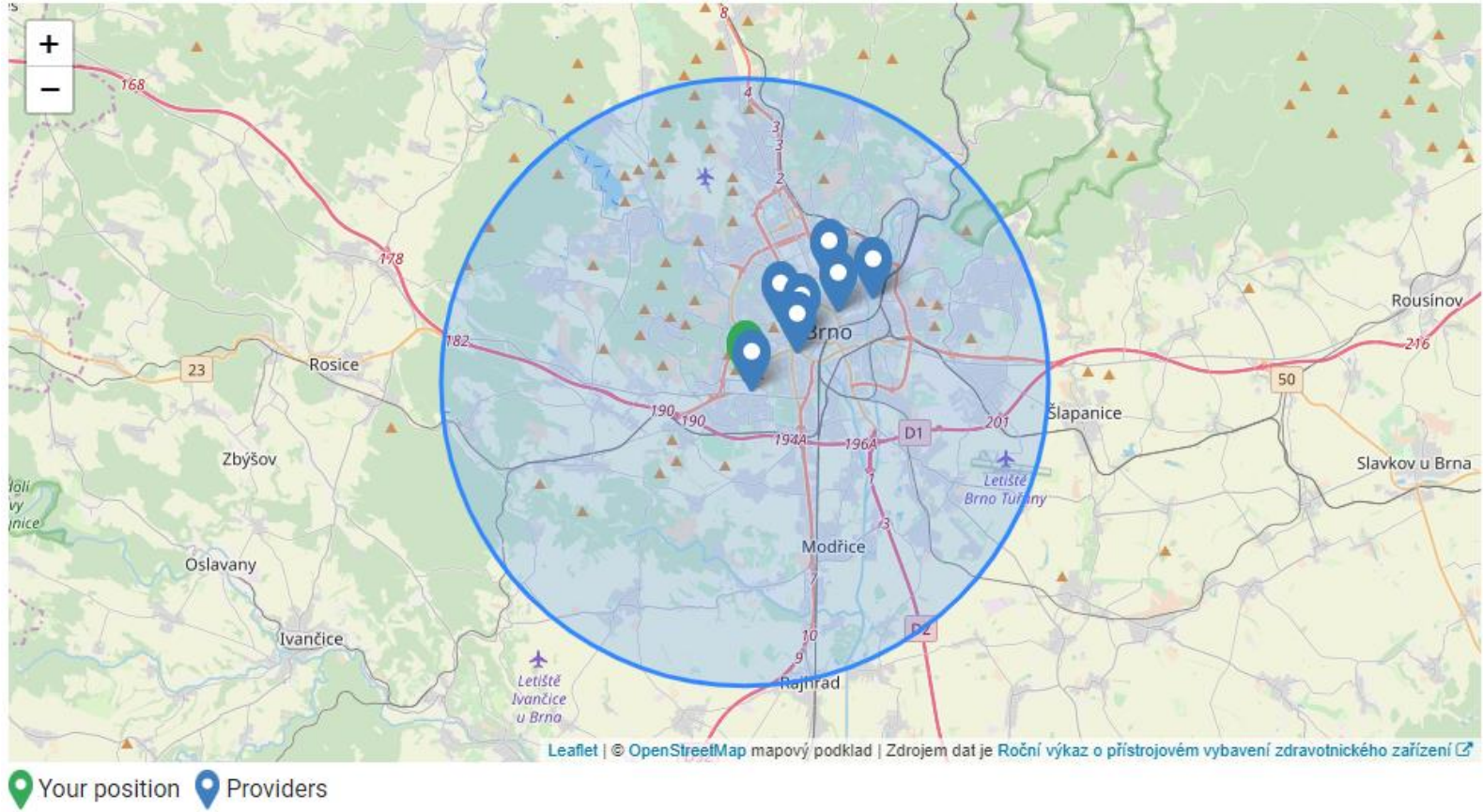

\begin{tabular}{|c|c|c|c|c|}
\hline Fakultní nemocnice Brno & $0,39 \mathrm{~km}$ & 21 prístrojủ & Detail Q & Navigovat 4 \\
\hline Nemocnice Milosrdných bratři, prisspěvková organizace & $1,94 \mathrm{~km}$ & 9 prístrojů & Detail Q & Navigovat 4 \\
\hline Masarykủv onkologický ústav & $2,23 \mathrm{~km}$ & 6 prístrojủ & Detail Q & Navigovat 4 \\
\hline Fakultni nemocnice U sv. Anny v Brnĕ & $2,41 \mathrm{~km}$ & 15 přistrojů & Detail Q & Navigovat 1 \\
\hline Úrazová nemocnice v Brně & $3,79 \mathrm{~km}$ & 7 prístrojů & Detail Q & Navigovat 1 \\
\hline SurGal Clinic s.r.o. & $4,35 \mathrm{~km}$ & 2 prístroje & Detail Q & Navigovat 1 \\
\hline Vojenská nemocnice Brno & $5,01 \mathrm{~km}$ & 5 přistrojů & Detail Q & Navigovat 1 \\
\hline
\end{tabular}

Figure 5: Search of the nearest healthcare providers

During the entire period of application run up to now, we have not experienced any long-term service outages or performance fluctuations, not even during the moments of automatic daily updates of a persistent layer from an external resource containing information about healthcare providers (National Registry of Healthcare Providers). In order to present a complete dataset on our MME, import of all healthcare providers records from across the Czech Republic will definitely be the next step forward. This improvement will follow essential changes in the Czech legislation, where the Ministry of Health of the Czech Republic is the leading competent authority.

\section{REFERENCES}

[BYPA15] BIUK-AGHAI, ROBERT P. ; YANG, MUYE ; PANG, PATRICK CHEONG-IAO ; AO, WAi HOU ; FONG, SIMON ; SI, YAIN-WhAR: A map-like visualisation method based on liquid modelling. In: Journal of Visual Languages \& Computing Bd. 31 (2015), S. 87-103

[Dung13] DUNGLAS, KÉVIN: Persistence in PHP with the Doctrine ORM : Packt Publishing Ltd, 2013. - Google-Books-ID: ONtdAgAAQBAJ ISBN 978-1-78216-411-1

[Jenk00] Jenkins.

URL https://jenkins.io/index.html. - abgerufen am 201811-23. — Jenkins

[Kirk16] KIRK, ANDY: Data Visualisation: A Handbook for Data Driven Design: SAGE, 2016. Google-Books-ID: wNpsDAAAQBAJ — ISBN 978$1-4739-6631-4$

[Leaf00] Leaflet - an open-source JavaScript library for interactive maps. URL https://leafletjs.com/. - abgerufen am 2018-11-23 
[MeWa17] Meloncon, L. ; WARner, E.: Data visualizations: A literature review and opportunities for technical and professional communication. In: 2017 IEEE International Professional Communication Conference (ProComm), 2017, S. 19

[Momj01] MOMJIAN, BRUCE: PostgreSQL: introduction and concepts. Bd. 192: AddisonWesley New York, 2001

[Murr17] MURRAY, SCOTT: Interactive Data Visualization for the Web: An Introduction to Designing with: O'Reilly Media, Inc., 2017.
Google-Books-ID: $\quad$ NGwvDwAAQBAJ ISBN 978-1-4919-2132-6

[Post00] PostgreSQL: About. URL https://www.postgresql.org/about/. - abgerufen am 2018-11-23

[Výka00] Výkazy na rok 2017 ÚZIS ČR. URL http://www.uzis.cz/vykazy/vykazy-rok-2017\#T. - abgerufen am 2018-11-23

[What00] What is a Container. URL https://www.docker.com/resources/what-container. abgerufen am 2018-11-23 